\title{
Effect of Addendum Height and Teeth Number on Asymmetric Normal Contact Ratio Spur Gear Based on Load Sharing
}

\author{
P. Marimuthu*, G. Muthuveerappan \\ Mechanical Engineering, Indian Institute of Technology Madras, Chennai \\ *Corresponding Author: pmiitm@gmail.com
}

Copyright (C) 2014 Horizon Research Publishing All rights reserved.

\begin{abstract}
This study explores the influence of some gear parameters such as addendum height, teeth number and module on load sharing aspect and the subsequent stress analysis. The multi pair contact model in finite element technique is used for a reasonable accurate prediction of the stresses with the application of load at high pressure angle side. Also, a unique Ansys parametric design language code is developed for this study. Finally the increase in addendum height results to increase the bending stress for a load at critical loading point. However the increase in teeth number and module leads to decrease in the load sharing based bending and contact stresses.
\end{abstract}

Keywords Addendum Height, Asymmetric Gear, Bending Stress, Load Sharing, Multi Pair Contact Analysis

\section{Introduction}

Gear drives are the most preferable drives for transmission of torque and motion between parallel, non-parallel and intersecting shafts. In particular the asymmetric gear drives are suitable for unidirectional power transmission drives such as wind mill, helicopter main drives and turboprop engine gear drives etc. Conventional gear design is the simplest design procedure that yields less computational works and tooling compare with direct design. Inadequate contact and bending strength are the common criterion's which leads to the failure of the gears. Contact strength is important for design of through hardened gears and this contact strength can be improved by different heat treatment process like case hardening and shot peening, so also, the modification of the gear tooth geometry as asymmetric gear is the simplest way to achieve high contact strength. The bending strength is mainly influenced by the fillet radius due to stress concentration and it is highly improved by generation using full round cutters. The asymmetric gear is defined by two different base circles, as asymmetric gear has different pressure angles at the drive side and coast side. A reasonably accurate estimation of Load Sharing Ratio (LSR) based contact and bending stresses is required for high quality gear drives. This LSR and respective stresses can be found by using different Finite Element (FE) models such as single point loaded model, multi point loaded model and Multi Pair Contact Model (MPCM). The MPCM is one of the models that account the adjacent tooth effect. Hence, in the present study, the MPCM is adopted.

Kapelevich et al. (2000) proposed a new method such as area of existence for Direct Design ${ }^{\circledR}$ of asymmetric spur gear with reduced weight and optimized fillet region to improve gear strength. Litvin et al.(2000) proposed modified gear geometry with crowned pinion capable to reduced transmission error, bending and contact stress on high pressure angle side.

Deng et al.(2003) estimated the LSR based on bending stiffness for different standard pressure angle. Muni et al.(2007) optimized the fillet strength for direct design asymmetric Normal Contact Ratio (NCR) spur gear. Li (2008) investigated that the effect of addendum on contact and bending strength by using three dimensional (3D) finite element method and stated that increase in addendum influences to reduce load sharing at tip. Senthil Kumar et al.(2008) developed a non-standard asymmetric rack cutter to generate asymmetric gear and optimized the fillet strength with optimum profile shift. Thirumurugan and Muthuveerappan (2010,2011) developed a finite element model to accurately estimate the fillet stress based on load sharing for symmetric NCR spur gears. Furthermore, suggested that MPCM yields reasonably accurate than single point load model and found critical loading points for symmetric NCR and High Contact Ratio (HCR) gears based on load sharing.

It is also found that many literatures are available for influence of gear parameters over the bending and contact stresses. The existing works reveals that the load sharing effect is not considered on the stress analysis of asymmetric spur gear. So, in the present study, a LSR based maximum 
bending $\left(\left(\sigma_{t}\right)_{\max }\right)$ and contact stresses $\left(\left(\sigma_{H}\right)_{\max }\right)$ analysis for the conventionally designed asymmetric NCR spur gears has been attempted. In addition to that, the present work deals to estimate the influence of gear parameters such as addendum height $\left(\mathrm{h}_{\mathrm{a}}\right)$, teeth number $(\mathrm{z})$, module $(\mathrm{m})$ on the LSR based maximum bending and contact stresses in the asymmetric NCR spur gears.

\section{Synthesis and Conventional Design of Asymmetric Rack Cutter}

A conventional asymmetric rack cutter of addendum $\left(h_{a r}\right)$ of 1.25 module and dedendum of 1 module with full round tip (Fig.1) is considered in the present study for the parametric analysis. The cutter and gear parameter are listed in Table1.

Table 1. Gear parameters for MPCM

\begin{tabular}{|c|c|}
\hline Parameters & Value \\
\hline Number of teeth in the pinion $\left(z_{1}\right)$ & 40 \\
\hline Pressure angle(Drive side)- $\alpha_{o d}$ & $30^{\circ}$ \\
\hline Pressure angle(Coast side) $-\alpha_{o c}$ & $20^{\circ}$ \\
\hline Gear ratio $(i)$ & 1.0 \\
\hline Coefficient of asymmetry (k) & 1.1 \\
\hline Rim Thickness & $5 \mathrm{~m}$ \\
\hline Contact ratio-drive side $\left(\varepsilon_{d}\right)$ & 1.37 \\
\hline Contact ratio-coast side $\left(\varepsilon_{c}\right)$ & 1.71 \\
\hline \multicolumn{2}{|c|}{ Asymmetric rack cutter parameters } \\
\hline module & $1.0[\mathrm{~mm}]$ \\
\hline Tooth thickness $\left(t_{r}\right)$ & $1.5708[\mathrm{~mm}]$ \\
\hline Addendum $\left(\mathrm{h}_{\mathrm{ar}}\right)$ & 1.25 \\
\hline Dedendum $\left(\mathrm{h}_{\mathrm{fr}}\right)$ & 1.0 \\
\hline Profile shift $\left(\mathrm{x}_{1}=\mathrm{x}_{2}\right)$ & 0 \\
\hline Tip Radius $\left(A_{r}\right)$ & $0.3[\mathrm{~mm}]$ \\
\hline Cutter type & Full round \\
\hline \multicolumn{2}{|c|}{ Material properties } \\
\hline Young's Modulus (E) & $210 \mathrm{GPa}$ \\
\hline Poison's Ratio (v) & 0.3 \\
\hline
\end{tabular}

\section{Multi Pair Contact Analysis}

In this present work, two-dimensional (2D) three teeth full rim model (Fig. 2(a)) of MPCM is used to estimate the LSR, LSR based bending and contact stresses. The Ansys Parametric Design Language code (ANSYS 12.1) is developed to generate $2 \mathrm{D}$, three teeth full rim model. The material properties used for this present study are linear elastic, isotropic and homogeneous. In this study, plain strain condition is assumed. An eight nodded quadrilateral (in ANSYS, 2D-PLANE 82) with two degrees of freedom at each node is used to get Finite Element (FE) model of asymmetric NCR spur gear. The contact element (CONTA172) and target element (TARG169) are used to establish surface to surface contact between pinion and gear. The inner periphery of the gear is radially restrained in all direction and normal force $10 \mathrm{~N}$ with equivalent torque is applied at inner periphery of the pinion. The Augmented Legrangian contact algorithm is chosen by default. The convergence study is carried out to fix the element size at the fillet and contact region. The von Mises stress at pitch point and corresponding bending stress obtained at root are shown in Figs.3 (a) and 3(b) respectively. The LSR is estimated at every contact position using the Eq. 1 .

$$
L S R=\frac{\text { contact load at a pair }}{\text { Total contact load }}
$$

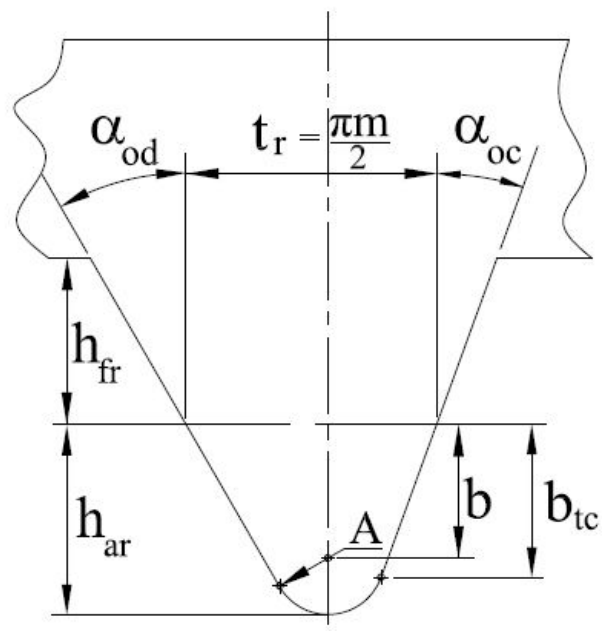

Figure 1. Conventional asymmetric rack cutter

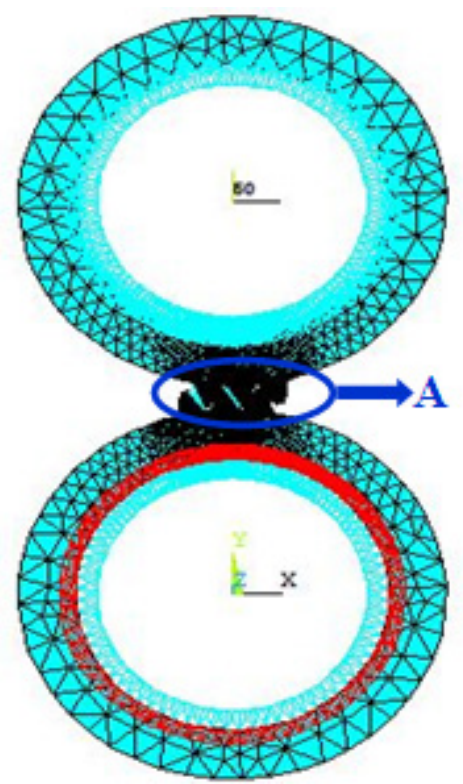

(a) 


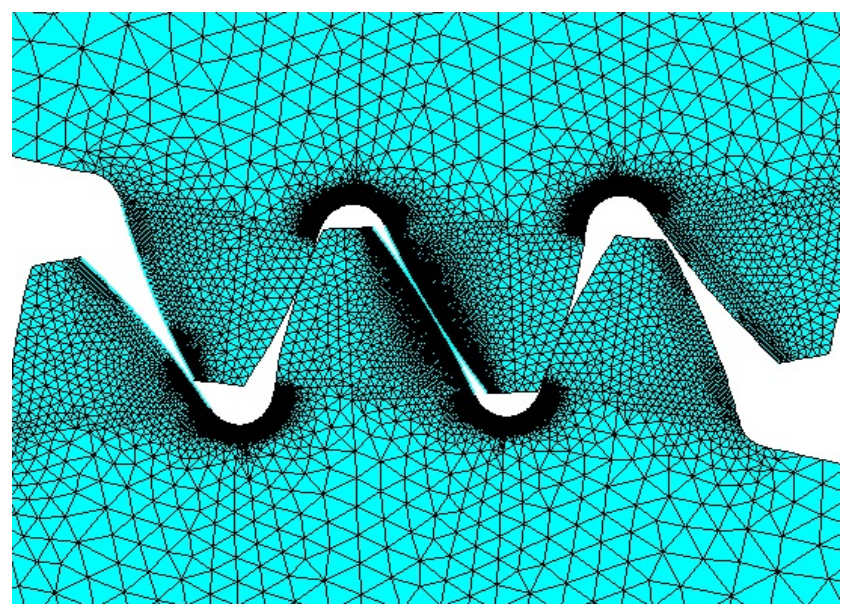

(b)

Figure 2. 2D Finite element model with boundary conditions. a). 2D three teeth full rim model, b). Magnification at A of 2(a).

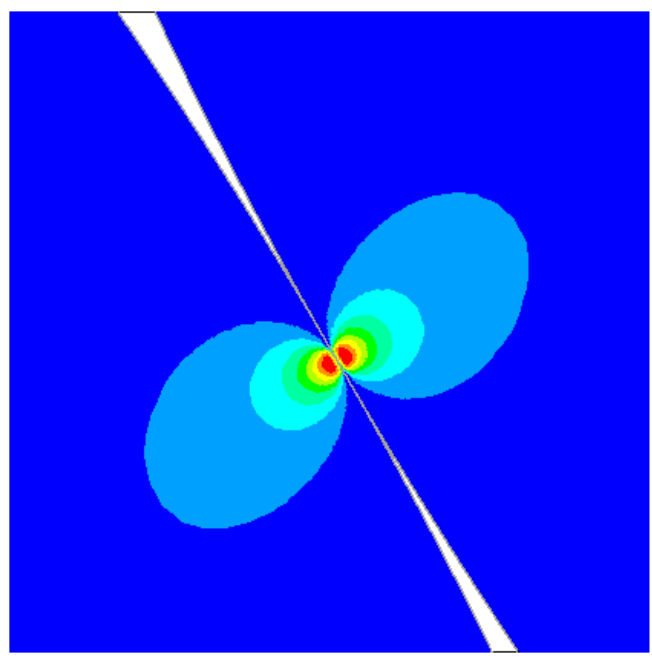

ANSYS 12.1

HODAL SOLUTION

$S T E P=1$

$\mathrm{SUB}=5$

SEQV (AVG)

PowerGraphics

PowerGrap
EFACET $=1$

AVRES $=$ Mat

$\mathrm{DMX}=.660 \mathrm{E}-03$

$\begin{aligned} \text { SMN } & =.2338-05 \\ \text { SMX } & =149.793\end{aligned}$

$\mathrm{ZV}=1$

$\begin{aligned} Z V & =1 \\ * D I S T & =.639047\end{aligned}$

$\mathrm{XF}=-.003654$

$\mathrm{YF}=20.063$

$\mathrm{YF}=20.0$
$\mathrm{Z}$-BUFFER

$.233 \mathrm{E}-05$

16.644

33.287

49.931

66.575
83.219

83.219
99.862

99.862
116.506

133.15
149.793

(a)

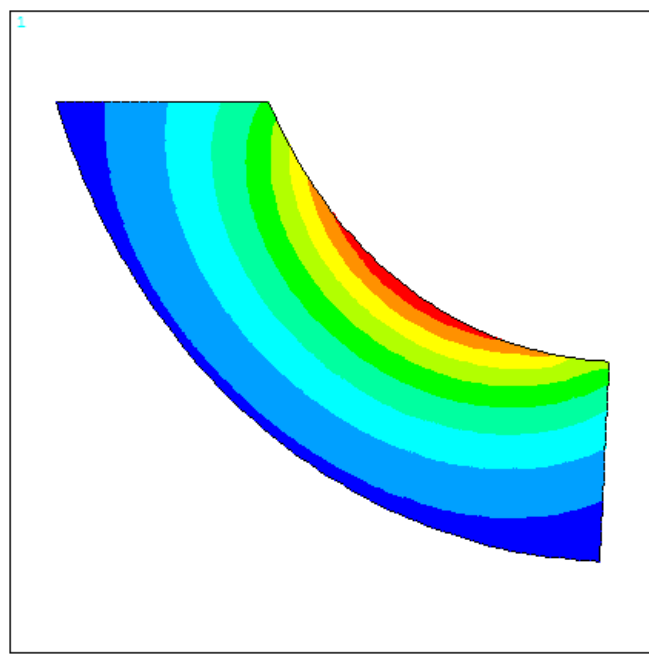

(b)

Figure 3. Stress plot for a load at high pressure angle side. a). von Mises stress plot for contact at pitch point, b). Bending stress at the fillet.

\section{Parametric Study on Asymmetric Spur Gear}

\subsection{Influence of Addendum Height}

The effects of addendum height on LSR, $\left(\sigma_{t}\right)_{\max }$ and $\left(\sigma_{\mathrm{H}}\right)$ ${ }_{\text {max }}$ are respectively shown in Figs. 4 (a), (b) and (c). Increase in addendum height $\left(\mathrm{h}_{\mathrm{a}}=1.2 \mathrm{~m}\right)$ above the standard addendum height $\left(\mathrm{h}_{\mathrm{a}}=1 \mathrm{~m}\right)$ reflects significant reduction of LSR at the Hihest Point of Tooth Contact (HPTC) and Lowest Point of Tooth Contact (LPTC). At the same time the LSR at the critical loading point Highest Point of Single Tooth Contact (HPSTC) increases (Fig. 4(a)), but the bending lever arm decreases. Therefore, the LSR based bending stress increases due to load at HPSTC. If the addendum height is reduced to 0.8 times of module like stub tooth, the LSR based bending stress decreases as shown in Fig. 4 (b). But the contact stress remains the same, as the LSR equals one at pitch point (Fig. 4(c)).

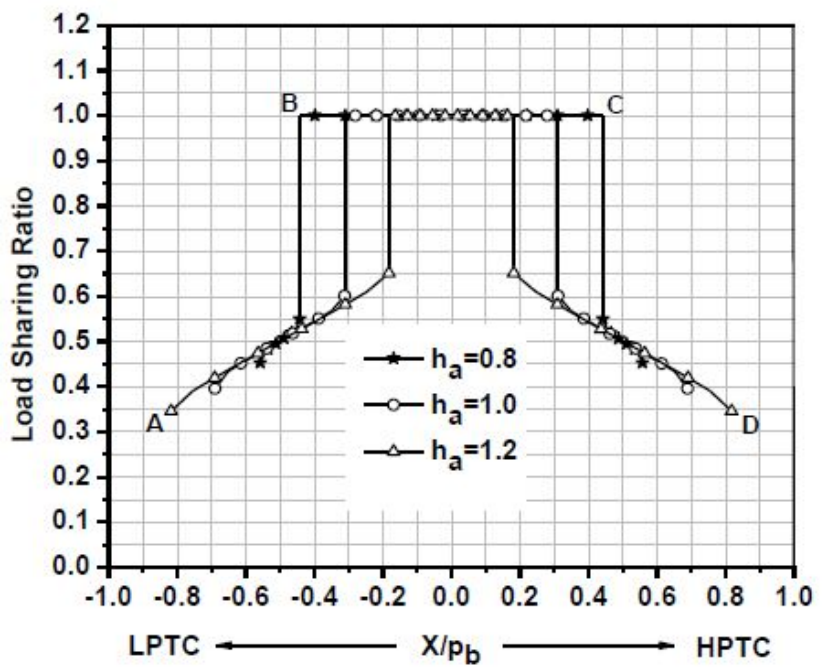

(a)

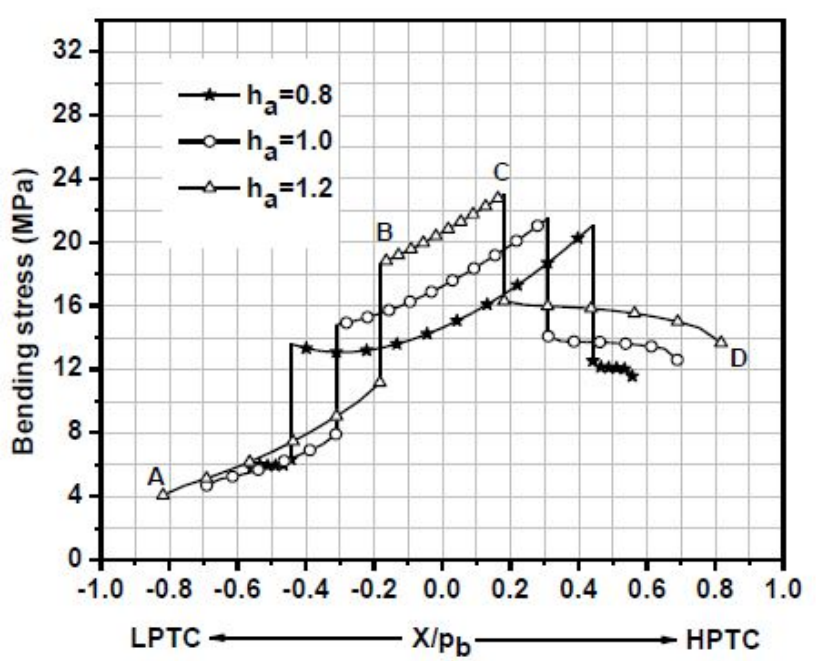

(b) 


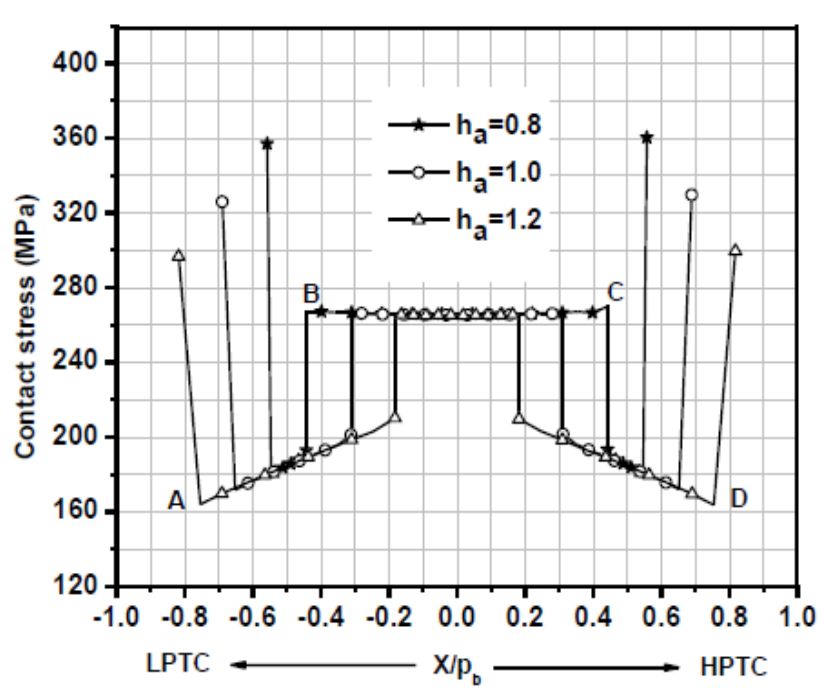

(c)

Figure 4. Effect of addendum height on LSR, LSR based bending and contact stresses for a load at high pressure angle side. $\left(m=1, z_{1}=40, i=1\right.$, $\alpha_{\mathrm{c}}=20^{\circ}, \alpha_{\mathrm{d}}=30^{\circ}$ ). a) LSR versus contact position. b) LSR based bending stress versus contact position. c) Contact stress versus contact position.

\subsection{Effect of Teeth Number}

The respective LSR and corresponding stresses (Bending and Contact stresses) estimated for different number of teeth in pinion and gear $\left(\mathrm{z}_{1}=\mathrm{Z}_{2}=20,40,60\right)$ are shown in Fig.5. There is a marginal decrease in the LSR at the LPTC and HPTC observed due to increase in teeth number on pinion and gear (Fig. 5(a)). At the same time the LSR at the critical loading point HPSTC increases to a smaller extent. However, the LSR based bending stress decreases for load at HPSTC (Fig. 5(b)). In addition to that the contact stress reduces significantly for contact at pitch point (Fig. 5(c)). These decreases are the usually expected trend for an increase in teeth number.

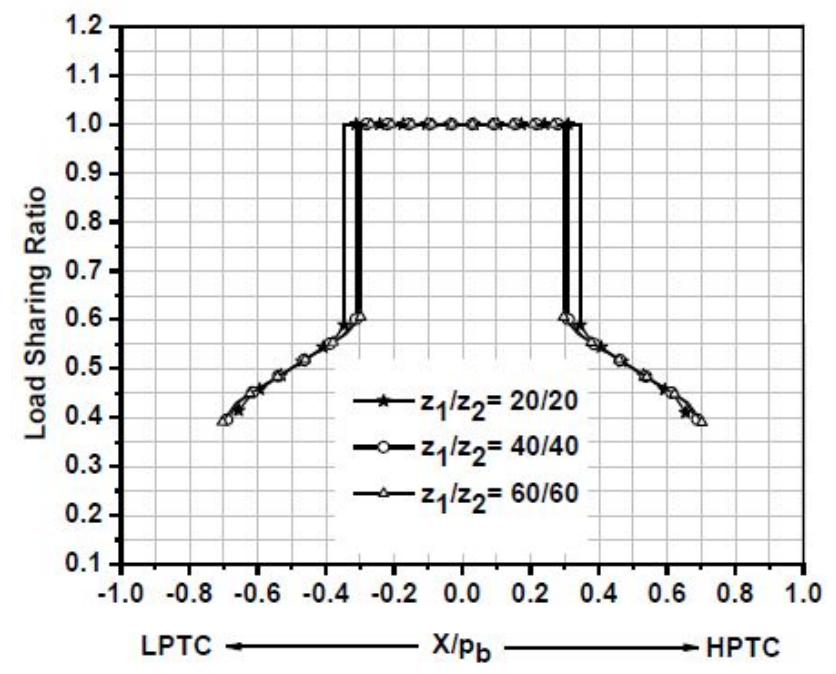

(a)

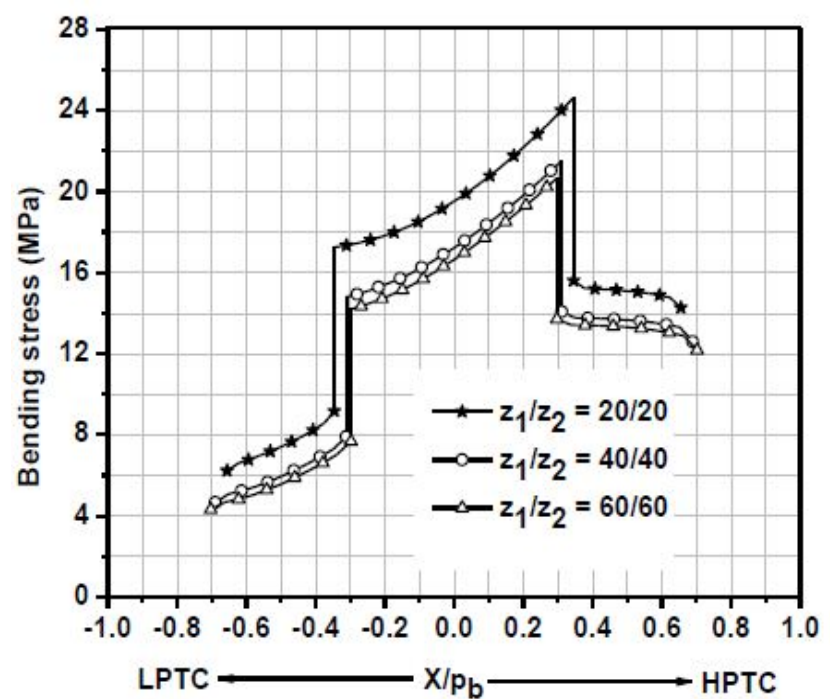

(b)

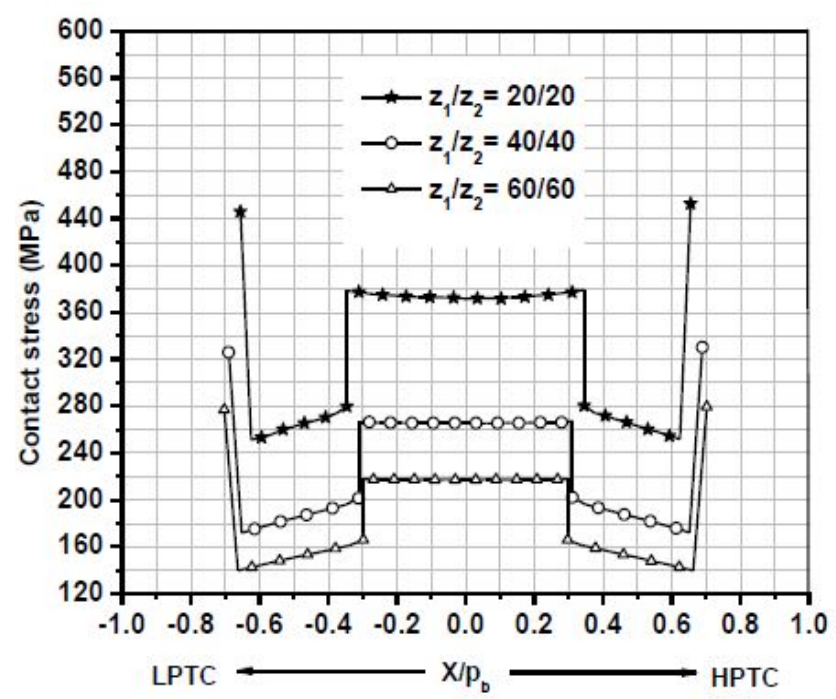

(c)

Figure 5. Effect of teeth number of pinion and gear on LSR, LSR based bending and contact stresses for a load at high pressure angle side. $\left(\mathrm{m}=1, \mathrm{z}_{1}\right.$ $\left.=40, i=1, \alpha_{c}=20^{\circ}, \alpha_{d}=30^{\circ}\right)$. a) LSR versus contact position. $b$ ) LSR based bending stress versus contact position. c) Contact stress versus contact position.

\subsection{Effect of Module}

The LSR, LSR based bending and contact stresses determined for various modules $(\mathrm{m}=1, \mathrm{~m}=2, \mathrm{~m}=4)$ is shown in Fig. 6. In this case, the size and other parameters of gears are kept constant $\left(\mathrm{r}_{01}=50\right.$ is fixed), accordingly module is varied from 1,2 and 4 . The bending stress is decreased tremendously as module increases as shown in Fig. 6(b), but there is only a small reduction on contact stress as well as load sharing ratio as shown in Figs. 6(c) and 6(a), because of a smaller change in radius of curvature at the contact points. 


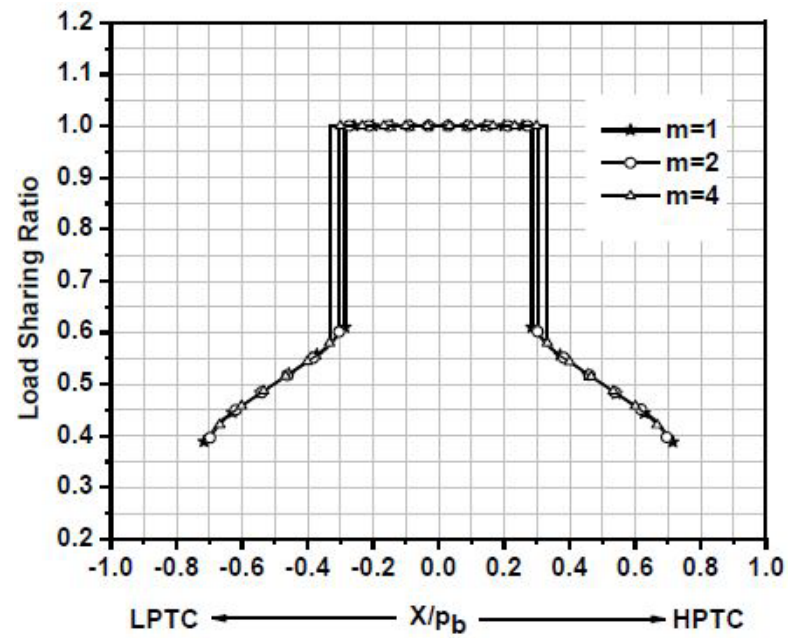

(a)

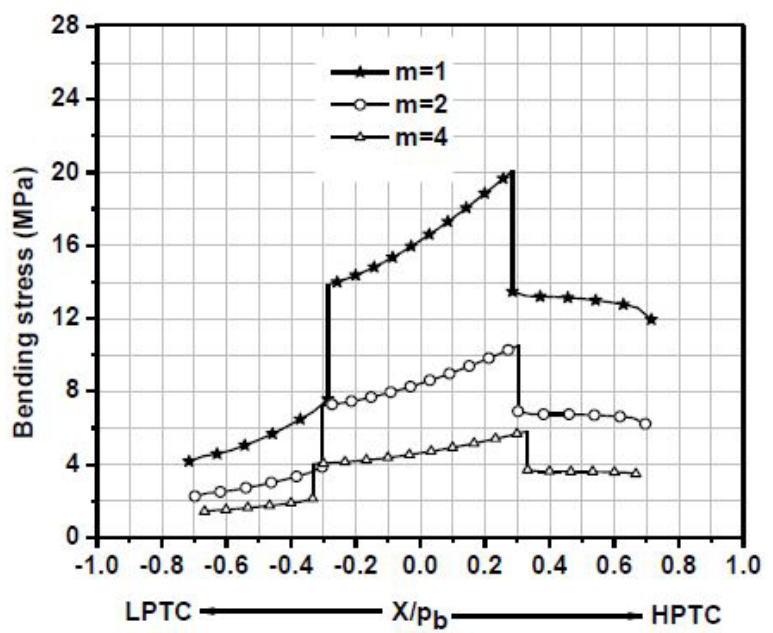

(b)

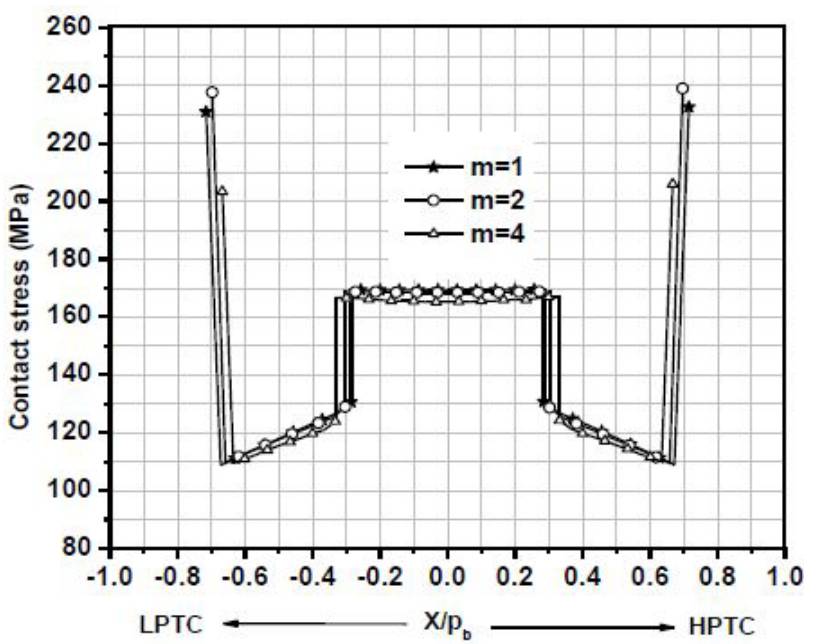

(c)

Figure 6. Effect of module on LSR, LSR based bending and contact stresses for a load at high pressure angle side. $\left(m=1, z_{1}=40, i=1, \alpha_{c}=20^{\circ}\right.$, $\alpha_{\mathrm{d}}=30^{\circ}$ ). a) LSR versus contact position. b) LSR based bending stress versus contact position. c) Contact stress versus contact position.

\section{Conclusions}

The effects of addendum height, teeth number and module are determined considering load sharing between the teeth pair. Also finite element based MPCM technique is used to find the bending and contact stresses and based on this study, the following inferences are made.

1. In the LSR based stress analysis, increase in the addendum height increases the bending stress due to high bending moment arm.

2. The increase in teeth number reduces the bending and contact stresses at HPSTC and pitch point respectively.

3. There is a $50 \%$ reduction of bending stress for load at HPSTC due to increase in the module noticed for same size of the gears $\left(r_{01}=50\right.$ is fixed). But the contact stress is not influenced significantly

\section{REFERENCES}

[1] Deng, G., Nakanishi, T. and Inoue, K. (2003) Bending load capacity enhancement using and asymmetric tooth profile. JSME, 46 (3), 1171-1177.

[2] Kapelevich, A.L., (2000) Geometry and design of involute spur gears with asymmetric teeth. Mechanism and Machine Theory, 35, 117-130.

[3] Li, S. (2008) Effect of addendum on contact strength, bending strength and basic performance parameters of a pair of spur gears. Mechanism and Machine Theory, 43 (12), 1557-1584.

[4] Litvin,F.L., Lian, Q. and Kapelevich,A.L. (2000) Asymmetric modified spur gear drives: reduction of noise, localization of contact, simulation of meshing and stress analysis. Computer Methods Applied Mechanics Engineering, 188, 363-390.

[5] Muni,D.V., Senthil Kumar, V. and Muthuveerappan. G. (2007) Optimization of Asymmetric Spur Gear Derives for Maximum Bending Strength Using Direct Gear Design Method. Mechanics Based Design of Structures and Machines, 35, 127-145.

[6] Senthil Kumar, V., Muni,D.V. and Muthuveerappan,G. (2008) Optimization of asymmetric spur gear drives to improve the bending load capacity. Mechanism and Machine Theory, 43, 829-858.

[7] Thirumurugan, R. and Muthuveerappan,G. (2010) Maximum fillet stress analysis based on load sharing in normal contact ratio spur gear drives. Mechanics Based Design of Structures and Machines, 38, 204-226.

[8] Thirumurugan, R. and Muthuveerappan,G. (2011)Critical loading points for maximum fillet and contact stresses in normal and high contact ratio spur gears based on load sharing. Mechanics Based Design of Structures and Machines,39, 118-141. 